\title{
APLICAÇÃO DO ÓLEO ESSENCIAL DE CANELA EM VAGENS DE AMENDOIM COM SECAGEM CONVECTIVA E ARMAZENAMENTO
}

\author{
T. C. C GORAYEB*, G.T LUCAS, J. A.TAKEMOTO, Y. P. O. NISHIYAMA, THOMÉO J. C. \\ Universidade Estadual Paulista - Instituto de Biociências, Letras e Ciências Exatas de São José do \\ Rio Preto. Departamento de Engenharia e Tecnologia de Alimentos.
}

e-mail: tegorayeb@yahoo.com.br

\begin{abstract}
RESUMO
O presente trabalho tem por objetivo avaliar a eficiência da aplicação do óleo essencial de canela contra a infestação fúngica e a produção de aflatoxina em vagens de amendoim, seguido de secagem convectiva e posterior armazenamento em condições ambientais controladas. Foi aplicado o óleo essencial de canela nas vagens de amendoim com contaminação de origem, que foram secas em monocamada e camada espessa a $40{ }^{\circ} \mathrm{C}$ e armazenadas em umidade e temperatura controladas. Na secagem em monocamada e armazenamento por 30 dias, as inibições da contaminação fúngica diminuíram nas concentrações de óleo de 50 e $250 \mathrm{mg} \cdot \mathrm{mL}^{-1}$ e a aflatoxina total não foi detectada nas vagens impregnadas por óleo na umidade relativa de $75,3 \%$ e $25^{\circ} \mathrm{C}$. Nos resultados obtidos das inibições nas vagens armazenadas após a secagem em camada espessa na ausência do óleo de canela, a contaminação fúngica se manteve alta, assim como a de aflatoxina, porém não foram detectadas contaminações fúngica e de aflatoxina nas vagens impregnadas com o óleo na concentração de 50 e $250 \mathrm{mg} \cdot \mathrm{mL}^{-1}$ por 30 dias, nas umidades relativa do ambiente de 75,3\% e 90,3\%; mas em 60 dias e em 90 dias ocorreram contaminações altas de aflatoxina somente no ambiente com umidade de 90,3\%. Apesar da boa inibição propiciada pelo óleo essencial de canela aplicado em vagens de amendoim com a microbiota de origem, como as concentrações necessárias foram elevadas, o custo foi elevado e ocorreu um forte odor nas vagens.
\end{abstract}

\section{INTRODUÇÃO}

A canela (Cinnamomum zeylanicum) tem muitas propriedades biológicas, sendo uma delas a sua capacidade antifúngica, inseticida, bactericida e parasiticida (CARMO, 2008). Diante dessas propriedades inibitórias sobre o desenvolvimento de fungos e da importância das espécies do grupo Aspergillus flavus, que apresentam potencial para síntese de aflatoxina em cultura do amendoim, é necessário a realização de estudos para avaliar a sua eficiência na eliminação desta contaminação (VIEGAS et al., 2005).

A parede celular é o principal mecanismo de defesa e sobrevivência de alguns fungos. No caso dos fungos Aspergillus, $90 \%$ dela é constituída por polissacarídeos e proteínas, formando uma estrutura tridimensional que mantém sua integridade estrutural, proporcionando uma defesa física à célula e protegendo-a de qualquer hostilidade do meio (ABAD et. al., 2010).

A ação dos óleos essenciais pode se dar por vários mecanismos, mas o mais aceito 
para explicar sua ação biofúngica se baseia na desestruturação da parede celular causada pela ação conjunta das interações hidrofóbicas das e eletrostáticas entre o polímero positivamente carregado (polissacarídeos e proteínas da parede celular dos fungos), com as macromoléculas que carga negativa como os lipossacarídeos e proteínas que compõem os óleos essenciais (GOY et al., 2009, ABAD et. al., 2010).

Entre os diversos métodos para o controle de infestações fúngicas e consequente redução de teores de micotoxinas, a aplicação de agentes biológicos de controle em amendoim, algodão e milho vem aumentando, o que certamente se configura como um exemplo de estratégia bem sucedida (AMAIKE; KELLER, 2011), ainda que poucos trabalhos estejam disponíveis abrangendo etapas do processo de beneficiamento de vagens, grãos e sementes, tais como a secagem e o armazenamento.

Araujo, et al., (2014) relatam que muitos produtos agrícolas são normalmente colhidos com teor de umidade inadequado para uma correta e eficiente conservação. Pela legislação brasileira, o teor de umidade de vagens de amendoim deve ser de, no máximo, $11 \%$ e de $8 \%$ para grãos (BRASIL, 2003). Em geral, as vagens de amendoim são retiradas do solo com umidade em média de $65 \%$ b.s. deixadas secar ao sol até atingirem em média de $16 \%$ quando as condições ambientais são favoráveis. Nos beneficiadores as vagens são admitidas com teores máximos de $18 \%$, sendo as vagens posteriormente secas até o teor de umidade de armazenamento em secadores de leito fixo e camada espessa.

Após a etapa de secagem, as vagens de amendoim são acondicionadas em big bags de $1000 \mathrm{~kg}$ ou em sacos de $50 \mathrm{~kg}$ com armazenamento seguro em armazém com umidade relativa (UR) inferior a $70 \%$, sob temperatura de no máximo $30^{\circ} \mathrm{C}$ (EMBRAPA, 2004; GORAYEB et al. 2009).
Nesse contexto, o presente trabalho tem por objetivo avaliar a eficiência da aplicação do biofungicida óleo essencial de canela, contra a infestação fúngica e a produção de aflatoxina, quando da aplicação seguida de secagem em monocamada e camada espessa e armazenamento em condições ambientais controladas. Os resultados obtidos são importante indicador aos profissionais do agronegócio sobre a pertinência de se aplicar tais agentes na prevenção da infestação de microrganismos micotoxigênicos.

\section{MATERIAIS E MÉTODOS}

Para as secagens foi empregado um secador de leito fixo e fluxo cruzado, em escala de bancada que pode operar em monocamada ou em camada espessa, como mostra a Figura 1.

Figura 1: Secador de leito fixo e câmara de secagem.

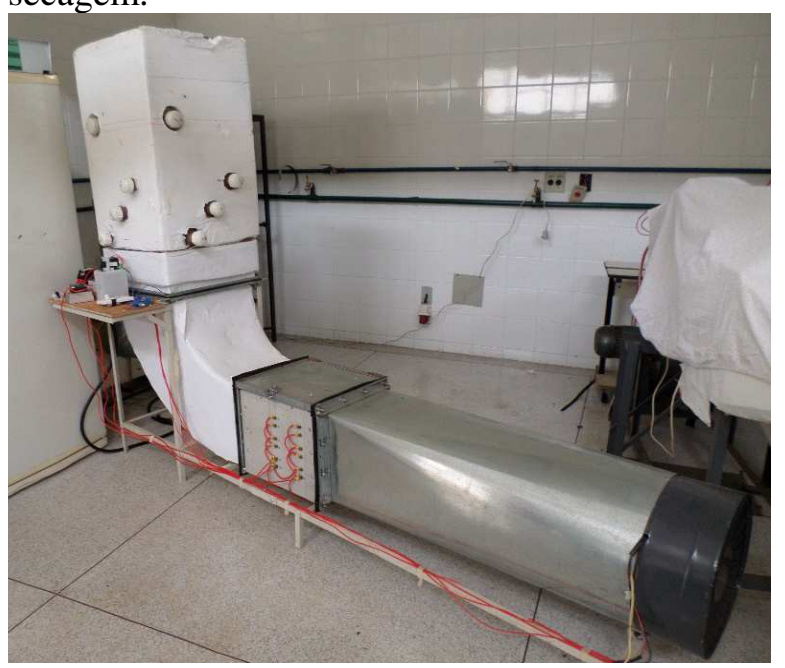

Fonte: Elaborado pela autora

As amostras de vagens de amendoim Runner IAC 886 foram gentilmente cedidas pela Cooperativa dos Plantadores da Zona de Guariba - COPLANA, de Jaboticabal, São Paulo. No início e término das secagens umidade das vagens foi determinada pelo método padrão da estufa a $105^{\circ} \mathrm{C}$ por 24 horas (INSTITUTO ADOLFO LUTZ, 2008). 
As análises de aflatoxina $\mathrm{B}_{1}, \mathrm{~B}_{2}, \mathrm{G}_{1} \mathrm{e}$ $\mathrm{G}_{2}$ foram realizadas por cromatografia líquida de alta eficiência por análise de fluorecência, seguindo-se o método 991.31 da Association of Official Agricultural Chemists International (AOAC, 2000). Esta análises foram realizadas pela empresa JLA Brasil, de Marília - SP.

O óleo essencial de canela (Cinnamomum zeylanicum), utilizado na inibição (in sito), foi adquirido na empresa, FERQUIMICA Indústria e Comércio Ltda. No laudo, a constituição dos componentes principais foram de aldeído cinâmico $81 \%$, Cumarina 3\%, álcool cinâmico $3 \%$, Benzaldeido $3 \%$ e Estireno com 3\%.

\subsection{Secagem em monocamada com a aplicação do óleo essencial de canela e armazenamento em condições controladas}

Foram pesados cerca de $200 \mathrm{~g}$ das amostras de vagens de amendoim Runner IAC 886, com ausência de aflatoxina. Em seguida as amostras foram colocadas em peneiras, seguido de aspersão de $20 \mathrm{~mL}$ da emulsão de óleo de canela diluído em Tween $80^{\circledR}$, a $0,01 \%$ (v/v), na concentração de 0,50 e $250 \mathrm{mg} \cdot \mathrm{mL}^{-1}$. Foram retiradas três amostras de $5 \mathrm{~g}$ de vagens para a realização da umidade inicial e, em seguida, as peneiras foram inseridas no secador, sendo a secagem foi realizada a $40^{\circ} \mathrm{C}$ e $1,5 \mathrm{~m} / \mathrm{s}$ de velocidade do ar. Foram feitas pesagens em intervalos regulares, em uma balança semi analítica, acompanhando-se a perda de massa até atingir massa constante. Realizou-se as medições da umidade relativa do ar e temperatura do ambiente, durante a secagem.

Para o ajuste das curvas de cinética de secagem das vagens de amendoim, utilizou-se o modelo de Page (1949), apresentado na Equação 1, sendo os ajustes dos modelos aos dados experimentais realizados por meio do software Microcal Oringin, versão 6.0.

$$
R U=\exp \left(-K^{n} t^{n}\right.
$$

Após as secagens, foram pesadas duas amostras de 25 gramas de vagens de amendoim e colocadas em duas cestas de nylon, as quais foram inseridas em potes com soluções salinas de cloreto de sódio, propiciando um ambiente com umidade relativa de $75,3 \%$ a $25^{\circ} \mathrm{C}$ (RESNIK; CHERIFE, 1988), simulando condições similares a umidade média do município de Jaboticabal que é de 70,6\% (JABOTICABAL, 2015). Os potes foram armazenados durante 30 dias em câmara $\mathrm{DBO}$ a $25 \pm 1^{\circ} \mathrm{C}$, sendo periodicamente monitorada a umidade relativa interna e a temperatura por meio do termohigrômetro.

\subsection{Secagem em camada espessa das vagens de amendoim com aplicação do óleo essencial de canela e armazenamento em condições controladas}

Para a aspersão da emulsão de águaóleo-Twenn $80^{\circledR}$, as vagens foram pesadas, distribuídas na peneira com área de $0,26 \mathrm{~m}^{2} \mathrm{e}$ acondicionadas na caixa plástica, com área da seção de $0,68 \mathrm{~m}$ de comprimento, por $0,38 \mathrm{~m}$ de largura e altura de $0,38 \mathrm{~m}$, de modo a simular uma esteira transportadora de vagens de amendoim. Sobre as vagens, a emulsão foi aspergida por meio de bomba de engrenagens e dois aspersores agrícolas de cones cheios por 15 segundos, como mostra a Figura 2.

A secagem em camada espessa foi realizada na temperatura de $40^{\circ} \mathrm{C}$ e $2,8 \mathrm{~m} / \mathrm{s}$ de velocidade do ar, temperatura próxima a utilizada na indústria $\left(38^{\circ} \mathrm{C}\right)$. Foram retiradas amostras de diferentes posições do leito e pesagens foram feitas em intervalos regulares de tempo até atingirem massa que a umidade base seca estivesse abaixo de $8 \%$. Foram realizadas as medições da umidade relativa do ar e temperatura do ambiente, durante a secagem, com o uso de um termohigrômetro digital. 
Figura 2: Imagem das caixas do experimento calibração do volume aspergidos.

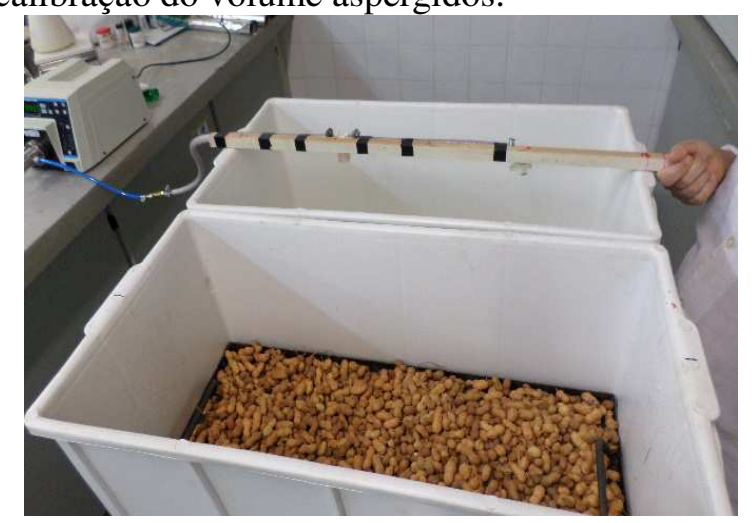

Fonte: Elaborado pela autora

Após a secagem, foram pesadas quatro amostras de 2,3 $\mathrm{kg}$ de vagens de amendoim, que foram colocadas em sacos de ráfia e acondicionados em caixas plásticas contendo solução salina de cloreto de sódio e de cloreto de bário, sendo que este último proporciona umidade relativa de $90,3 \%$ a $25^{\circ} \mathrm{C}$ (RESNIK; CHERIFE, 1988), na temperatura de $25^{\circ} \mathrm{C}$. Duas caixas abrigaram vagens sem aplicação de óleo essencial e duas na concentração de $50 \mathrm{mg} \cdot \mathrm{mL}^{-1}$. As caixas foram armazenadas durante 90 dias na $\mathrm{DBO}$ a $25 \pm 1^{\circ} \mathrm{C}$.

As análises da inibição da contaminação fúngica das vagens de amendoim foram realizadas por meio do método descrito por Swanson et al. (1992), que propicia a contagem de unidades formadoras de colônias de microrganismos.

As análises de aflatoxina dos amendoins foram realizadas com o preparo das amostras após o armazenamento, onde $50 \mathrm{~g}$ de vagens coletadas de cada saco de ráfia foram debulhadas manualmente no total, em triplicata.

No experimento de armazenamento das vagens secas em monocamada, com a inibição da microbiota origem por óleo essencial de canela, os resultados foram analisados utilizando ANOVA para o delineamento experimental adotando blocos ao acaso em parcela subdividida ("Split-plot") realizados com três repetições para a análise de Unidade Formadora de Colônias com o software Minitab 16 (Minitab Inc., Pensilvânia, EUA). Os valores médios foram comparados por meio do teste de Tukey em $\mathrm{p} \leq 0,05$.

\section{RESULTADOS E DISCUSSÃO}

\subsection{Secagem em monocamada}

No experimento com secagem em monocamada, a umidade inicial das amostras era de $12,59 \%$ (b. s.). Após a aspersão de 20 $\mathrm{mL}$ de água destilada e de emulsões de óleo com concentrações de 50 e $250 \mathrm{mg} \cdot \mathrm{mL}^{-1}$, as vagens iniciaram a secagem em monocamada com uma média de $16,44 \%$ e terminaram os ensaios com umidade de equilíbrio média de $3,70 \%$ (b. s.).

Os parâmetros do modelo Page sofreram pouca variação devido à aplicação da emulsão de óleo essencial, o que se podia esperar devido à baixa concentração de óleo na emulsão. De modo geral o resultado foi satisfatório, uma vez que o coeficiente de determinação foi superior a 0,98, como mostra a Tabela 2.

Tabela 2: Parâmetros de ajuste pelo modelo de Page da cinética de secagem das vagens de amendoim da variedade Runner IAC 886, na ausência e presença do óleo essencial de canela nas concentrações de 0,50 e $250 \mathrm{mg} / \mathrm{mL}$ e coeficientes de determinação $\mathrm{R}^{2}$, realizadas a $40^{\circ} \mathrm{C}$

\begin{tabular}{cccc}
\hline $\begin{array}{c}\text { Concentração } \\
(\mathbf{m g} / \mathbf{m L})\end{array}$ & $\mathbf{K}$ & $\mathbf{n}$ & $\mathbf{R}^{\mathbf{2}}$ \\
\hline $\mathbf{0}$ & $0,0148 \pm 0,0009$ & $0,6943 \pm 0,0104$ & 0,9959 \\
$\mathbf{5 0}$ & $0,0153 \pm 0,0015$ & $0,6845 \pm 0,0154$ & 0,9915 \\
$\mathbf{2 5 0}$ & $0,0169 \pm 0,0022$ & $0,6705 \pm 0,0207$ & 0,9832 \\
\hline
\end{tabular}

As curvas de secagem ajustadas pelo modelo de Page, no ajuste dos dados experimentas da secagem de vagens de amendoim, apresentou um alto coeficiente de determinação e está apresentada na Figura 3. As curvas de secagem mostraram que após 24 
horas, a umidade diminuiu sensivelmente, aproximando-se da umidade de equilíbrio, com valores inferiores aos requeridos pela legislação para vagens, de $11 \%$.

Figura 3: Curvas de secagem das vagens de amendoim com a aplicação da emulsão de óleo essencial de canela nas concentrações de 0,50 e $250 \mathrm{mg} \cdot \mathrm{mL}^{-1}$ para a secagem em monocamada a $40{ }^{\circ} \mathrm{C}$ ajustada pelo modelo de Page.

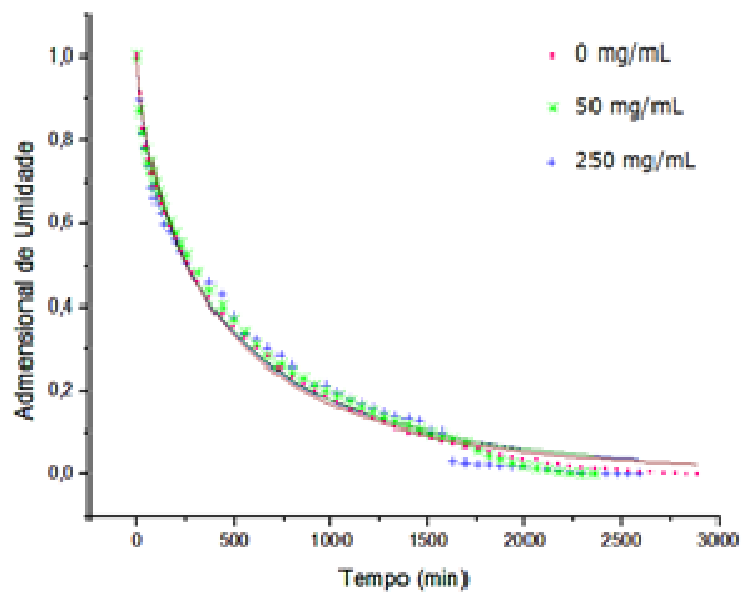

Nos resultados apresentados na Tabela 3 , foi possível verificar inibição de 58,3\% da infestação fúngica para a concentração de 50 mg.mL $L^{-1}$ e de $76,71 \%$ na concentração de 250 $\mathrm{mg} \cdot \mathrm{mL}^{-1}$ após 30 dias do armazenamento, não ocorrendo a produção de aflatoxina.

Tabela 3: Inibição da contaminação fúngica de origem (log de UFC. ${ }^{-1}$ ) das vagens de amendoim por óleo essencial de canela armazenadas em umidade controlada por 30 dias

\begin{tabular}{c|c|c}
\hline $\begin{array}{c}\text { Concentração } \\
\text { da emulsão do }\end{array}$ & \multicolumn{2}{|c}{$\begin{array}{c}\text { Período de armazenamento } \\
\text { (dias) }\end{array}$} \\
\cline { 2 - 3 } $\begin{array}{c}\text { óleo essencial } \\
\text { de canela } \\
\text { (mg.mL }\end{array}$ & $\mathbf{0}$ & $\mathbf{3 0}$ \\
\hline $\mathbf{0}$ & $8,47 \pm 0,21 \mathrm{aA}$ & $8,67 \pm 0,24 \mathrm{aA}$ \\
\hline $\mathbf{5 0}$ & $7,98 \pm 1,37 \mathrm{aA}$ & $4,31 \pm 1,84 \mathrm{bB}$ \\
\hline $\mathbf{2 5 0}$ & $6,71 \pm 1,41 \mathrm{aB}$ & $2,02 \pm 0,98 \mathrm{bB}$ \\
\hline
\end{tabular}

Médias seguidas da mesma letra minúscula, nas concentrações, não diferem entre si a $5 \%$ de significância, pelo teste de Tukey.
Médias seguidas da mesma letra maiúscula, nos períodos, não diferem entre si a $5 \%$ de significância, pelo teste de Tukey.

Nota-se que, com a aplicação da emulsão com óleo de canela, a contaminação e a aflatoxina mostraram-se bem inferiores, na umidade relativa de $75,3 \%$.

\subsection{Secagem em camada espessa de vagens de amendoim}

A emulsão do óleo essencial foi aplicada com os aspersores mantidos por 15 segundos em cima da peneira e após $12 \mathrm{hs}$ foram levados para a câmara de secagem. Durante a secagem, a umidade relativa do ambiente foi medida, variando entre $47,3 \%$ no início para 56,4\%. A temperatura do ambiente, durante a secagem em camada espessa, manteve-se estável em média $30 \pm 1$ ${ }^{\circ} \mathrm{C}$.

Os resultados da média de umidade das vagens antes e após a aplicação do óleo de canela foi de 10,50 $\pm 0,5 \%$ (b. s), e 11,35 \pm $0,4 \%$ (b. s.), respectivamente. Pode-se observar que a temperatura média das camadas foi de $37,2,36,7$ e $35,7{ }^{\circ} \mathrm{C}$ nas camadas 1, 2 e 3, respectivamente. Uma redução pequena, mas esperada para esse tipo de ensaio. No entanto, o comportamento da umidade das vagens em relação às camadas foi atípico, diminuindo da base para o topo, quando se deveria esperar o oposto, sendo $7,49 \%$ b. s. na camada $1,6,53 \%$ b. s. na camada 2 e $6,37 \%$ b. s. na camada 3 . Possivelmente, a pequena altura do leito, as variações ambientais das condições termodinâmicas do ar e a pequena amostragem devem ter ocasionado esse comportamento. De todo modo, as variações foram pequenas e pode-se considerar a umidade final uniforme em toda a camada espessa.

Nos resultados da umidade das vagens de amendoim durante o armazenamento estão apresentados na Tabela 4. Nas vagens armazenadas na caixa com umidade U1 - 
$\mathrm{NaCl}$ sem a aplicação da emulsão do óleo de canela $(0 \mathrm{mg} / \mathrm{mL})$, observou-se que a umidade das vagens apresentaram um aumento de 0,87 $\%$ b. s. Para as vagens armazenadas na caixa com a mesma umidade, mas com a aplicação da emulsão do óleo de canela na concentração de $50 \mathrm{mg} \cdot \mathrm{mL}^{-1}$, o aumento foi em média de $2,46 \%$ b. s.

As amostras armazenadas na caixa com umidade $\mathrm{U} 2-\mathrm{BaCl}_{2}$, sem a aplicação da emulsão do óleo de canela, C1 - $0 \mathrm{mg} / \mathrm{mL}$, apresentaram um aumento em média de 3,45 $\%$ b. s., com o valor em média de $13,75 \%$ b. s., e na $\mathrm{U} 2-\mathrm{BaCl}_{2}, \mathrm{C} 2-50 \mathrm{mg} / \mathrm{mL}$, com o aumento de $5,47 \%$ b. s. atingindo a umidade média de $12,27 \%$ b. $\mathrm{s}$. Em ambos os armazenamentos as umidades ultrapassaram o limite permitido pela legislação, que é superior a $11 \%$ b. s. (BRASIL, 2003).

Tabela 4: Umidade das vagens de amendoim com ausência e presença de óleo essencial de canela, armazenadas durante 90 dias

\begin{tabular}{|c|c|c|c|c|c|c|}
\hline \multirow{2}{*}{$\begin{array}{c}\text { Umidade } \\
\text { relativa do } \\
\text { armazenamento } \\
\text { das vagens } \\
\end{array}$} & \multirow[b]{2}{*}{$\begin{array}{c}\text { Concentração } \\
\left(\mathbf{m g . m L} \mathbf{L}^{-1}\right)\end{array}$} & \multicolumn{4}{|c|}{ Período (dias) } & \multirow{2}{*}{$\begin{array}{l}\text { Média e } \\
\text { desvio } \\
\text { padrão }\end{array}$} \\
\hline & & $\mathbf{0}$ & 30 & 60 & 90 & \\
\hline \multirow{2}{*}{$\begin{array}{c}\mathbf{U} \mathbf{1}-\mathbf{~ N a C l} \\
(75,3 \%)\end{array}$} & C1 - 0 & $10,5 \pm 0,5 \mathrm{~cd}$ & $11,5 \pm 0,1 \mathrm{~cd}$ & $11,7 \pm 0,4 \mathrm{~cd}$ & $11,1 \pm 0,1 \mathrm{~cd}$ & $11,1 \pm 0,53$ \\
\hline & C2- 50 & $6,8 \pm 0,7 \mathrm{~cd}$ & $10,3 \pm 0,2 \mathrm{~d}$ & $10,7 \pm 1,1 \mathrm{~cd}$ & $11,0 \pm 0,3 \mathrm{~cd}$ & $11,0 \pm 1,95$ \\
\hline \multirow{2}{*}{$\begin{array}{c}\mathbf{U} \mathbf{2}-\mathbf{B a C l}_{\mathbf{2}} \\
(90,3 \%)\end{array}$} & $\mathrm{C} 1-\mathrm{O}$ & $10,5 \pm 0,5 \mathrm{~cd}$ & $13,9 \pm 0,2 b$ & $17,1 \pm 0,8 \mathrm{a}$ & $16,6 \pm 0,7 \mathrm{a}$ & $16,6 \pm 3,03$ \\
\hline & C2- 50 & $6,8 \pm 0,7 \mathrm{~cd}$ & $12,3 \pm 0,1 b c$ & $17,7 \pm 1,0 \mathrm{a}$ & $16,8 \pm 0,8 \mathrm{a}$ & $16,8 \pm 4,99$ \\
\hline
\end{tabular}

Médias seguidas da mesma letra minúsculas, não diferem entre si a 5\% de significância, pelo teste de Tukey.

Na Tabela 5 são apresentados os resultados da inibição da contaminação fúngica de origem para as amostras na ausência do óleo essencial de canela e com a aplicação da emulsão do óleo com $50 \mathrm{mg} / \mathrm{mL}$, armazenadas em ambiente com a umidade $75,32 \%$ e $90,3 \%$, foi realizada a análise de variância das médias e observou-se que os resultados da a contaminação fúngica não apresentaram diferenças significativas nos diferentes períodos e nas diferentes concentrações de aplicação do óleo essencial de canela com os valores de 8,01 a 8,48 em Log UFC/g para a testemunha. As amostras armazenadas com a aplicação de óleo essencial de canela na concentração C2 (50 $\mathrm{mg} \cdot \mathrm{mL}^{-1}$ do óleo), apresentaram valores inferiores, mas não expressivos.

Os pesquisadores, Tripathi e Kumar, (2007), isolaram os fungos de sementes de amendoim armazenadas em lojas no município de Uttar Pradesh, Índia Oriental. O óleo de canela (Cinnamomum tamala Nees and Eberm) foi aplicado nas $200 \mathrm{~g}$ de sementes, nos volumes de 250 e $380 \mu \mathrm{L} / \mathrm{mL}$, secos em estufa e armazenadas as sementes por 6 meses em recipientes de capacidade 250 $\mathrm{mL}$. O óleo de canela apresentou uma inibição de $30.0 \%$ contra o Aspergillus flavus e de 23,0 \% para o A. Niger na concentração de $250 \mu \mathrm{L} / \mathrm{mL}$. Resultados superiores aos desse ensaio, porém inferiores aos ensaios de monocamada apresentados na Tabela 3.

Atualmente são realizados muitos trabalhos de inibição dos fungos in vitro, com o uso de óleos essenciais, porém, no momento de analisar as aplicações in sito, as dificuldades quanto à metodologia são grandes, principalmente quanto a métodos que apresentem como realizar a aplicação das vagens e como armazená-las, o que sugere mais trabalhos de aplicação. 
Tabela 5: Unidade formadora de colônia (UFC/g) das vagens de amendoim com ausência e presença de óleo essencial de canela, armazenadas durante 90 dias

\begin{tabular}{|c|c|c|c|c|c|c|}
\hline \multirow{2}{*}{$\begin{array}{c}\text { Umidade relativa } \\
\text { do } \\
\text { armazenamento } \\
\text { das vagens }\end{array}$} & \multirow[b]{2}{*}{$\begin{array}{c}\text { Concentração } \\
\left(\mathbf{m g} \cdot \mathbf{m L}^{-1}\right)\end{array}$} & \multicolumn{4}{|c|}{ Período (dias) } & \multirow[b]{2}{*}{$\begin{array}{l}\text { Média Log } \\
\text { UFC.g }^{-1}\end{array}$} \\
\hline & & $\mathbf{0}$ & 30 & 60 & 90 & \\
\hline \multirow{2}{*}{$\begin{array}{c}\mathbf{U} \mathbf{1}-\mathbf{N a C l} \\
(75,3 \%)\end{array}$} & C1 - 0 & $8,01 \pm 0,7 \mathrm{a}$ & $8,25 \pm 0,5 \mathrm{a}$ & $8,25 \pm 0,5 \mathrm{a}$ & $8,50 \pm 0,2 \mathrm{a}$ & $8,25 \pm 0,2$ \\
\hline & C2- 50 & $7,52 \pm 2,1 \mathrm{a}$ & $8,17 \pm 0,7 \mathrm{a}$ & $8,17 \pm 0,7 \mathrm{a}$ & $6,20 \pm 0,2 \mathrm{a}$ & $7,51 \pm 0,93$ \\
\hline \multirow{2}{*}{$\begin{array}{c}\mathbf{U} \mathbf{2}-\mathbf{B a C l}_{\mathbf{2}} \\
(90,3 \%)\end{array}$} & C1 - o & $8,01 \pm 0,7 \mathrm{a}$ & $8,48 \pm 0,4 \mathrm{a}$ & $8,48 \pm 0,4 \mathrm{a}$ & $8,26 \pm 0,2 \mathrm{a}$ & $8,31 \pm 0,22$ \\
\hline & C2- 50 & $7,52 \pm 2,1 \mathrm{a}$ & $8,37 \pm 0,1 \mathrm{a}$ & $8,37 \pm 0,1 \mathrm{a}$ & $8,35 \pm 0,9 \mathrm{a}$ & $8,15 \pm 0,42$ \\
\hline
\end{tabular}

Médias seguidas da mesma letra minúsculas, não diferem entre si a 5\% de significância, pelo teste de Tukey.

A Tabela 6 apresenta os resultados da produção de aflatoxina pelos fungos de contaminação de origem das vagens de amendoim, na ausência da aplicação do óleo essencial de canela (testemunha) e com a aplicação da emulsão do óleo na concentração
$50 \mathrm{mg} / \mathrm{mL}$. A média dos resultados obtidos foram submetida à análise de variância, que apontou somente o fator "Concentração de óleo essencial de canela" como significativo a $5 \%(\mathrm{p}=0,036)$.

Tabela 6: Média dos níveis de aflatoxina total das amostra de grãos de amendoim armazenadas nas vagens durante 90 dias, com a presença e ausência de óleo essencial de canela

\begin{tabular}{|c|c|c|c|c|c|c|}
\hline \multirow{2}{*}{$\begin{array}{c}\text { Umidade do } \\
\text { ambiente } \\
(\%)\end{array}$} & \multirow{2}{*}{$\begin{array}{c}\text { Concentração } \\
\left(\mathbf{m g} \cdot \mathbf{m L}^{-1}\right)\end{array}$} & \multicolumn{4}{|c|}{ Período (dias) } & \multirow{2}{*}{$\begin{array}{c}\text { Média da } \\
\text { Aflatoxina total } \\
\left(\mu \mathrm{g} . \mathrm{kg}^{-1}\right) \\
\end{array}$} \\
\hline & & $\mathbf{0}$ & 30 & 60 & 90 & \\
\hline \multirow{2}{*}{$\begin{array}{c}\mathbf{U 1} \text { - NaCl } \\
(75,3 \%) \\
\end{array}$} & C1 - 0 & ND & $468,4 \mathrm{~d}$ & $2338,9 \mathrm{~b}$ & $1350,83 \mathrm{c}$ & 1039,53 \\
\hline & C2- 50 & ND & ND & ND & ND & ND \\
\hline \multirow{2}{*}{$\begin{array}{c}\mathbf{U} 2-\mathbf{B a C l}_{\mathbf{2}} \\
(90,3 \%)\end{array}$} & C1 - 0 & ND & $1196,43 \mathrm{c}$ & $1071,17 \mathrm{c}$ & $3312,71 \mathrm{a}$ & 1395,08 \\
\hline & C2- 50 & ND & ND & $8,11 \mathrm{e}$ & $1350,86 \mathrm{c}$ & 339,74 \\
\hline
\end{tabular}

ND - Os resultados menores que o Limite de Detecção do Método (LDM)

Médias seguidas da mesma letra minúsculas, não diferem entre si a 5\% de significância, pelo teste de Tukey.

Quanto aos teores iniciais das testemunhas com a ausência e presença do óleo essencial de canela na concentração de $50 \mathrm{mg} / \mathrm{mL}$, a produção de aflatoxina não foi detectada (ND). Após 30 dias ocorreu um aumento significativo na produção de aflatoxina nas amostras armazenada em ambas as umidades relativas com a ausência da aplicação do óleo essencial de canela, não sendo detectada nas amostras com a aplicação de óleo. No armazenamento de 90 dias, a produção de aflatoxina nas duas amostras com a ausência da aplicação do óleo essencial de canela, apresentaram um aumento significativo de 2338,9 e $1071,17 \mu \mathrm{g} . \mathrm{kg}^{-1}$, nas umidades U1 e U2, respectivamente.

Os resultados com a aplicação do óleo essencial de canela apresentaram teores de 
aflatoxina inferiores aos limites exigidos pela legislação vigente (BRASIL, 2003), na condição de armazenamento até 90 dias só para a umidade relativa de $75,3 \%$ (U1), ocorrendo a presença nas condições de umidade relativa de $90,3 \%$ (U2) em níveis elevados.

\section{CONCLUSÕES}

A eficiência do óleo essencial de canela contra a microbiota de origem com a secagem em monocamada, após a aspersão, mostrou-se eficiente reduzindo a infestação fúngica, após o período de trinta dias no armazenamento em condições de temperatura e umidade relativa controladas. Os índices foram inferiores aos exigidos por lei, não permitindo a presença de aflatoxina em umidade similar à do município de Jaboticabal - SP. Quanto ao ensaio com secagem em camada espessa, observou-se produção de aflatoxinas nas condições de umidade relativa elevada, ocorrendo a presença só no período de noventa dias de armazenamento.

A aplicação dos óleos essenciais mostrou-se promissora para o uso antes da etapa de secagem em amendoim, principalmente por prevenir o uso de agrotóxicos. No entanto, um odor forte de canela pode interferir nas características sensórias, proporcionando um odor característico nos grãos, além do custo do óleo ser alto.

\section{REFERÊNCIAS}

ABAD, A.; FERNÁNDEZ-MOLINA, J. V.; BIKANDI, J.; RAMÍREZ, A., MARGARETO, J.; SENDINO, J.; HERNANDO, F. L.; PONTÓN, J.; GARAIZAR, J.; REMENTERIA, A. What makes Aspergillus fumigatus a successful pathogen? Genes and molecules involved in invasive aspergillosis.

Revista
Iberoamericana de Micologia, Barcelona, v. 27, n. 4, p.155-182, 2010.

AMAIKE S.; KELLER N. P. Aspergillus flavus. Annual Review of Phytopathology. Paolo Alto, v. 49, p. 107-33, 2011.

ARAUJO, W. D.; GONELI A. L. D.; SOUZA C. M. A.; GONÇALVES A. A.; VILHASANTI H. C. B. Propriedades físicas dos grãos de amendoim durante a secagem. R. Bras. Eng. Agríc. Ambiental, Campina Grande, v.18, n.3, p.279-286, 2014.

\section{ASSOCIATION OF OFFICIAL} AGRICULTURAL CHEMISTS INTERNATIONAL (AOAC). AOAC official method 991.31: aflatoxins in corn, raw peanuts and peanut butter: immunoaffinity column (aflatest) method. Washington, DC, p. 49.2.18, 2000 .

BRASIL. Ministério da Saúde. Agência Nacional de Vigilância Sanitária. Resolução RDC n ${ }^{\circ} 172$, de 04 de julho de 2003. Poder Executivo, de 07 de julho de 2003. Diário Oficial da União, Poder Executivo, Brasília, DF, 7 jul. 2003. Seção 1. Disponível em: <http://portal.anvisa.gov.br>. Acesso em: 11 set. 2012.

CARMO, E. S.; LIMA, E. O.; SOUZA, E. L.; SOUSA, F. B. Effect of Cinnamomum zeylanicum Blume essential oil on the growth and Morphogenesis of some potentially pathogenic Aspergillus species. Brazilian Journal of Microbiology, São Paulo, v. 39, p. 91-97, 2008.

EMBRAPA. MANUAL de Boas Práticas Agrícolas e Sistema APPCC. Brasilia, 2004. 101 p. (Série: Qualidade e Segurança dos Alimentos).

GORAYEB, T.C.C., CASCIATORI, F.P., DEL BIANCHI, V.L.; THOMEO, J.C. 
HACCP plan proposal for a typical brazilian peanut processing company. Food Control, Guildford, v. 20, p. 671-676, 2009.

GOY, R. C.; BRITTO, D.; ASSIS, O. B. G. A Review of the Antimicrobial Activity of Chitosan. Polímeros: Ciência e Tecnologia, São Carlos, v. 19, n 3, p. 241-247, 2009.

INSTITUTO ADOLFO LUTZ (IAL). Métodos químicos e físicos para análise de alimentos. Normas analíticas do Instituto Adolfo Lutz. 3. ed. São Paulo: IMESP, 2008. v. 1 , p. 98-99.

JABOTICABAL - SP. [Mountain View]: Google, c2015. Disponível em: $<$ https://www.google.com.br/maps/place/Jabo ticabal+-+SP>. Acesso em: 30 mar. 2015.

PAGE, C. Factors Influencing the Maximum Rate of Drying Shelled Corn in Layers. West Lafayette, MSc Thesis, Purdue University. 1949.

RESNIK, S. L.; CHERIFE, J. Proposed theoretical water activity values at various temperatures for selected solutions to be used as reference sources in the range of microbial growth. Journal of Food Protection, Des Moines, v. 51, n. 5, p. 419-423, May 1988.

SWANSON, K. M.; BUSTA, F. F.; PETTERSON, E. H.; JOHNSON, M. G. Colony count methods. In: VANDEZANT, C.; SPLITTOESSER, D. S. (Ed.). Compendium of methods for the microbiological examination of foods. New York: American Public Health Association, 1992.

TRIPATHI, N. N.; KUMAR, N. Putranjiva roxburghii oil: a potential herbal preservative for peanuts during storage. Journal of Stored Products Research, Oxford, v. 43, n., p. 435442, 2007.
VIEGAS, E. C.; SOARES, A.; CARMO, M. G. F.; ROSSETTO, C. A. V. Toxicidade de óleos essenciais de alho e casca de canela contra fungos do grupo Aspergillus flavus. Horticultura Brasileira, Brasília, v. 23, n. 4, p. 915-919, out./dez. 2005.

\section{AGRADECIMENTOS}

Agradecemos o apoio da Cooperativa dos Plantadores da Zona de Guariba COPLANA, de Jaboticabal, São Paulo. 